\title{
Management of pertrochanteric fractures in patients over 90 years: In-hospital mortality rate, complications and associated risk factors
}

Mohamed Ghanem ${ }^{1,2^{*}}$ D, Jonas Garthmann ${ }^{1}$, Anja Redecker ${ }^{1}$, Annette Brigitte Ahrberg-Spiegl ${ }^{1}$ (D), Johannes Karl Maria Fakler ${ }^{1}$ and Ulrich Josef Albert Spiegl ${ }^{1}$ (B)

\begin{abstract}
Purpose: This study aims primarily to investigate the outcome following surgical management of pertrochanteric fractures of patients over 90 years compared to the outcome of a control group below 90 years under special consideration of the timing of surgery. The second aim was to analyze potential risk factors for early deaths in very old patients. This study allows us to draw conclusions to minimize complications linked to this particular age segment.

Methods: The study group consisted of very old patients aged 90 years and older. Geriatric patients aged between 60 and 89 years of age were part of the control group. Type A1 pertrochanteric fractures were typically treated by dynamic hip crews, type A2 and A3 fractures by femoral nails. Full weight bearing physiotherapy was initiated on the day after surgery to improve mobility and muscle strength.

Results: A total of 71 patients belonged to the study group (mean age: 92.5 years \pm 2.3 years), whereas 223 patients formed the control group (mean age: $79.9 \pm 7.4$ years). The mortality rate and the number of detected and documented complications were significantly higher in the study group ( $p=0.001 ; p=0.009$, respectively). Despite the significantly higher complication rate in the $>90$-year-old patients, there was no significant difference in the mean length of in-hospital-stay between the both groups (>90 yrs.: 12.1d; <90 yrs.: $13.1 \mathrm{~d}$ ) and the timing of surgery.

Conclusion: The number of co-morbidities, number of daily-administered medications and the time between admission and surgery have no impact on the outcome. We noticed a longer period between admission and surgery in very old patients who survived. Patients with pertrochanteric fractures should be screened for multimorbidity and cognitive disorders in a standardized manner.
\end{abstract}

Keywords: Pertrochanteric fractures, 90-year-old patients, Timing of surgery

\footnotetext{
* Correspondence: mohamed.ghanem@medizin.uni-leipzig.de

'Department of Orthopaedics, Traumatology and Plastic Surgery, University of Leipzig, Liebigstr. 20, 04103 Leipzig, Germany

2Department of Physical Therapy and Rehabilitation, University of Leipzig,

Leipzig, Germany
}

C The Author(s). 2021 Open Access This article is licensed under a Creative Commons Attribution 4.0 International License, which permits use, sharing, adaptation, distribution and reproduction in any medium or format, as long as you give appropriate credit to the original author(s) and the source, provide a link to the Creative Commons licence, and indicate if changes were made. The images or other third party material in this article are included in the article's Creative Commons licence, unless indicated otherwise in a credit line to the material. If material is not included in the article's Creative Commons licence and your intended use is not permitted by statutory regulation or exceeds the permitted use, you will need to obtain permission directly from the copyright holder. To view a copy of this licence, visit http://creativecommons.org/licenses/by/4.0/. The Creative Commons Public Domain Dedication waiver (http://creativecommons.org/publicdomain/zero/1.0/) applies to the data made available in this article, unless otherwise stated in a credit line to the data. 


\section{Introduction}

Proximal femoral fracture is one of the most common injuries in old age and is therefore one of the most important causes of morbidity and mortality in the older generation [1-3]. In Germany, around 90,000 proximal femoral fractures are expected annually [4-6]. The agedependent incidence shows an exponential increase ranging from 60/100,000 in the 60-64-year-old segment up to over $1300 / 100,000$ per year for people over the age of 85 [7]. On an average age of around 80 years, women are being affected in 3 out of 4 cases [8]. Due to the demographic development, several prognoses predict that the number of proximal femoral fractures will quadruplicate by 2050 [2, 3, 8-10]. With constantly increasing life expectancy and the shift in the age pyramid, we see, in addition to the increasing number of cases, the emergence of a new patient collective - that of the "very old", which confronts treating physicians with new challenges due to the mostly pre-existing multimorbidity. Therefore, we examined the particular age group between octogenarians and centenarians; that age group above 90 years that tends to expand demographically.

A geriatric patient is characterized by geriatric-typical multimorbidity and older age (mostly over 70 years). The so-called geriatric-typical multimorbidity is to be weighted far more heavily than the numerical age [1113]. Basically, it is represented by immobility, instability, incontinence, and intellectual changes [14]. Yet, patients over 90 years generally present with almost all of the above-mentioned criteria.

In general, fractures can be classified according to the internationally used classification of AO-Foundation, whereby a distinction is made between localization and dislocation [15]. Surgical management of proximal femoral fracture aims at minimizing postoperative pain and complications, immediate mobilization after surgery with full weight bearing of the extremity, rapid return to activities of daily living and prevention from falling. According to German guidelines, patients with pertrochanteric femoral fracture must be operated on within $24 \mathrm{~h}$ if the general condition of the patient allows this. This is based on literature reports [16-19] that have shown increased incidence of complications due to postponing surgery for more 24-48 h such as:

- increased morbidity and mortality,

- increased incidence of failure of osteosynthesis,

- increased rates of decubital ulcers and

- increased incidence of venous thrombosis and pulmonary embolism.

However, Zajonz et al. have shown that some geriatric patients with femoral neck fractures might benefit from elongated preoperative treatment protocol [20].
The primary aim of this study is to investigate the outcome following surgical management of pertrochanteric fractures of patients over 90 years compared to the outcome of a control group below 90 years under special consideration of the timing of surgery. Secondly, the aim was to analyze potential risk factors for early deaths in very old patients. This study allows us to draw conclusions to minimize complications linked to this particular age segment.

\section{Methods}

The study was performed at a single level I trauma center between January 2014 and December 2017. All geriatric patients (aged 60 and older) with isolated pertrochanteric femoral fractures after suffering from a low energy trauma were included. Further inclusion parameters were operative treatment of the fracture. All patients, who refused operative treatment and those who died prior surgery and all pathologic fractures due to malignancies were not included. Thereby, the following two study groups were generated: The study group consisted of very old patients aged 90 years and older. Geriatric patients aged between 60 and 89 years of age were part of the control group. The study was approved by the ethics committee of the local university. The vote -number of the audit authority is 166-20-ek. All procedures reported in this article were in accordance with the ethical standards of the institutional and/or national research committee and with the 1964 Helsinki declaration and its later amendments or comparable ethical standards.

Initially, all patients received conventional radiographs of the pelvis and the affected hip joint. In the rare cases of uncertainty of a fracture a computer tomography was performed. The fractures were classified according to the $\mathrm{AO}$ [15] and the treatment strategy was defined by the head of the department or the trauma surgeon on duty. Preoperative preparation was started and a rapid operative treatment was desired, ideally within $24 \mathrm{~h}$ after admission to the hospital. The following parameters were documented: Fracture classification, treatment strategy, numbers of diagnosis at admission, number of medications at admission, time interval between admission and surgery, and surgery time,. Thereby, the all diagnosis were grouped based on the affected organ and certain diseases as the following: cardiac, vascular, pulmonary, gastroenteric, liver, renal, thyroid, cerebal, spinal pathologies or autoimmune disease, diabetes mellitus, malignancies, obesity, and cachexia.

\section{Surgical algorithm}

Type A1 pertrochanteric fractures were typically treated by dynamic hip crews, type A2 and A3 fractures by proximal femoral nails. Thereby, long femoral nails were 
typically used in A3 fractures. Concomitant hip osteoarthritis and the individual fracture morphology as well as intraoperative complications had impact on the treatment concept such as performing hip arthroplasty or leading to a change of the strategy of osteosynthesis.

\section{Postoperative management}

All patients received conventional radiographs on the postoperative days $2-4$. Full weight bearing physiotherapy was initiated on the day after surgery to improve mobility and muscle strength. Dual X-Ray Absorptiometry (DXA) assessment and sufficient anti-osteoporotic therapy were recommended to all patients.

\section{Outcome parameters}

Patients were followed for the time of the in-hospital stay. The length of the in-hospital stay, all complications, revision surgeries and all deaths were analyzed. Revisions surgeries were defined as any unplanned surgery/ies during the in-patient stay after initial treatment of the fracture. Complications were defined as all documented events during the in-patient stay that were not existent during admission. These included death as the primary outcome parameter and revision surgery as the second outcome parameter as well as venous thrombosis, pulmonary embolism, pneumonia, urinary tract infections, anemia, gastrointestinal bleeding, cardiac events (arterial fibrillation, myocardial infarction); sepsis, decubitus, and electrolyte derailment.

\section{Statistics}

Statistical analyses were performed using standardized SPSS software 25.0 (SPSS ${ }^{\oplus}$, Inc. Chicago, USA). Statistical analysis was made using descriptive statistics. The mortality rate served as our primary outcome. For secondary outcome parameter we analyzed the rate of revision surgeries, the complication rate as well as the length of the in-hospital-stay. Thereby, all collected parameters were compared between both study groups. For this we took a closer look at the age and gender of the patient, classification and therapy of the proximal femur fracture, number of comorbidities and daily medications as well as time passed between admission and surgery. After an exploratory data analysis, selected parameters were further investigated by Pearson's test if parameters were distributed normally. Unpaired t-test was employed to compare the study group (patients $>90$ years) with the control group (patients 60-89 years old) in normally distributed parameters. A significance level of 0.05 was used.

\section{Results}

A total of 294 geriatric patients were identified with proximal femoral fractures. The study cohort is presented in Table 1.
A total of 71 patients belonged to the study group (mean age: 92.5 years \pm 2.3 years), whereas 223 patients formed the control group (mean age: $79.9 \pm 7.4$ years). The female gender dominated in both groups with a significant higher rate in the study group (control group: $67 \%$ versus study group: $87 \% ; p=0.003$ ). No differences were seen in the facture classification, the applied treatment strategy, the number of co-morbidities, and the number of daily medications between both groups. In contrast, the mortality rate and the number of detected and documented complications were significantly higher in the study group $(p=0.001 ; p=0.009$, respectively). Thereby, there were no significant differences between patients of the study group who died during the hospital stay compared to those who were dismissed alive with respect of age, number of co-morbidities, number of medications, number of complications as well as time between admission and surgery (Table 2). A more detailed list of the co-morbidities is illustrated in Table 3. All patients' parameters of all six patients who died are shown in Table 4.

In the control group 170 of 223 (76.2\%) showed no complications following surgical treatment whereas the proportion of uncomplicated courses in study group was only 42 of 71 (59.2\%). Most of the complications documented in both groups were general complications, particularly of urinary tract infections, anemia, pneumonia or acute deterioration of renal function. In contrast, surgical complications, particularly postoperative wound healing disorders and secondary failure of osteosynthesis was less frequently seen. Despite the significantly higher complication rate in the $>90$-year-old patients, there was no significant difference in the mean length of inhospital-stay between the both groups ( $>90$ yrs.: 12.1d; $<90$ yrs.: $13.1 \mathrm{~d}$ ) and the timing of surgery. Thereby, the average time between admission and surgery was $16.7 \mathrm{~h}$ in the very old patients who died and $31.3 \mathrm{~h}$ in those who survived the hospital stay, without being statistical significant $(p=0.14)$. All further potential risk factors that were analyzed (age, number of comorbidities, number of medications on admission, number of complications) were statistically not different between survivors and deaths of the study group. An overview of all complications of the study group is shown in Fig. 1. There was no significant difference with respect of the revision rate between the two study groups with 7 of $71(9.9 \%)$ in the study group compared to 20 of $223(9.0 \%)$ in the control group.

\section{Discussion}

In this retrospective study, we compared the outcome following surgical management of pertrochanteric fractures of patients over 90 years compared to the outcome of a control group aging 60 to 89. Particular attention 
Table 1 Study Cohort

\begin{tabular}{|c|c|c|c|c|c|}
\hline Paremeter & $>90$ years; $n=71$ & std & $60-89$ years; $n=223$ & Std & $p$-value \\
\hline Age & 92.5 & 2.3 & 79.7 & 7.4 & $<0.001$ \\
\hline Gender [\%] & $85.9 \%$ female & & $67.7 \%$ female & & 0.003 \\
\hline Classification $^{\mathrm{a}}$ & $\begin{array}{l}1.9 \\
\text { A1 fracture: } 21(30 \%) \\
\text { A2 fracture: } 33(46 \%) \\
\text { A3 fracture: } 17(24 \%)\end{array}$ & 0.7 & $\begin{array}{l}1.8 \\
\text { A1 fracture: } 83(37 \%) \\
\text { A2 fracture: } 95(43 \%) \\
\text { A3 fracture: }(20 \%)\end{array}$ & 0.8 & 0.26 \\
\hline Treatment strategy ${ }^{\mathrm{b}}$ & $\begin{array}{l}1.7 \\
\text { DHS: } 30(42 \%) \\
\text { PFN: } 41(58 \%)\end{array}$ & 0.8 & $\begin{array}{l}1.6 \\
\text { DHS: } 92(41 \%) \\
\text { PFN: } 124(56 \%) \\
\text { BA: } 3(1 \%) \\
\text { THA: }(2 \%)\end{array}$ & 0.6 & 0.90 \\
\hline $\mathrm{n} /$ comorbidities & 5.2 & 2.4 & 4.5 & 2.8 & 0.809 \\
\hline $\mathrm{n} /$ medications & 8.7 & 2.9 & 8.6 & 3.3 & 0.063 \\
\hline Time: admission to surgery [h] & 30.3 & 43.6 & 26.0 & 40.1 & 0.448 \\
\hline Revisions [\%] & 9.9 & & 9.0 & & 0.830 \\
\hline Mortality [\%] & 8.5 & & 0.9 & & 0.001 \\
\hline Complication [\%] & 41 & & 24 & & 0.005 \\
\hline $\mathrm{n} /$ complications & 0.6 & 0.8 & 0.3 & 0.7 & 0.009 \\
\hline In-hospital-stay [days] & 12.1 & 6.7 & 13.1 & 9.8 & 0.408 \\
\hline
\end{tabular}

$\mathrm{n}$ /comorbidities: Number of comorbidities; $\mathrm{n}$ /medications: number of medications at admission; time: admission to surgery [h]: time between admission to surgery in hours; $\mathrm{n} /$ complications: number of complications; std.: standard deviation

a 1 : fracture type $A 1 ; 2$ : fracture type $A 2 ; 3$ : fracture type $A 3$

b 1: dynamic hip screw (DHS); 2: proximal femur nail (PFN); 3: bipolar arthroplasty (BA); 4: total hip arthroplasty (THA); 5: others

was given to the overall complications, the impact of the number of co-morbidities, the number of daily medications as well as the time interval between hospital admission and surgical intervention on the outcome.

We observed a significantly higher incidence of mortality, general complications as well as surgery-related complications in patients $>90$ years. The number of comorbidities, number of medications, number of complications as well as time between admission and surgery did not have a significant impact of the outcome. This shows that an age above 90 years predisposes to higher mortality rate as well as to a higher rate of perioperative complication.

Though there are several reports in literature on proximal femoral fracture of the elderly, to the best of our knowledge, we did not encounter a comparative study that addresses this issue concerning the particular age group above 90 years.

Costa et al. evaluated data from over 16,000 patients after head replacement surgery for femoral neck fractures [21]. 6.7\% of the patients died in the hospital.

Based on studies of a collective of over 22,000 patients $[22,23]$ and a further retrospective study of around 38,000 patients [24], a hospital mortality ranged from 4.5 to $6.6 \%$.

In our study, we only examined the rate and type of inhospital complications. Several reports dealt with short term overall complication after discharge from hospital. Yet, the particular age segment above 90 years has not been analyzed specifically. Based on 93 re-examined patients after a femoral fracture near the hip joint, Simanski et al. reported a mortality after 12 months of $33 \%$ with a

Table 2 Potential risk factors of death in very old patients

\begin{tabular}{|c|c|c|c|c|c|}
\hline Parameters & Death $(n=6)$ & std & No death $(n=65)$ & Std & $P$-value ${ }^{+*}$ \\
\hline Age & 92.7 & 1.8 & 92.5 & 2.4 & 0.664 \\
\hline $\mathrm{n} /$ comorbidities & 6.0 & 3.3 & 5.1 & 2.4 & 0.538 \\
\hline $\mathrm{n} /$ medications & 9.0 & 4.6 & 8.7 & 2.8 & 0.689 \\
\hline Time: admission to surgery [h] & 16.7 & 13.4 & 31.3 & 45.0 & 0.142 \\
\hline $\mathrm{n} /$ complications & 0.8 & 1.0 & 0.5 & 0.7 & 0.448 \\
\hline
\end{tabular}

$\mathrm{n}$ /comorbidites: Number of comorbidities; $\mathrm{n}$ /medicactions: number of medications at admission; time: admission to surgery [h]: time between admission to surgery in hours; $\mathrm{n} /$ complications: number of complications; std.: standard deviation

* Mann-Whitney-U-Test 
Table 3 Frequency of comorbidities of treated patients in accordance of the affected organ

\begin{tabular}{lll}
\hline Parameter & > 90 years; $\boldsymbol{n}=\mathbf{7 0}$ & $\mathbf{6 0 - 8 9}$ years; $\boldsymbol{n}=\mathbf{2 2 3}$ \\
\hline Cardiac disease & $31(44,3 \%)$ & $91(40,8 \%)$ \\
Vascular disease & $15(21,4 \%)$ & $47(21,1 \%)$ \\
Pulmonary disease & $8(11,4 \%)$ & $25(11,2 \%)$ \\
Gastroenteric disease & $7(10 \%)$ & $23(10,3 \%)$ \\
Liver disease & $3(4,3 \%)$ & $6(2,7 \%)$ \\
Renal disease & $26(37,1 \%)$ & $35(15,7 \%)$ \\
Diabetes mellitus & $15(21,4 \%)$ & $65(29,1 \%)$ \\
Thyroid dysfunction & $11(15,7 \%)$ & $51(22,9 \%)$ \\
Autoimmune disease & $5(7,1 \%)$ & $4(1,8 \%)$ \\
Malignancy & $7(10 \%)$ & $23(10,3 \%)$ \\
Cerebral disease & $6(8,6 \%)$ & $26(11,7 \%)$ \\
Psychic disease & $26(37,1 \%)$ & $59(26,5 \%)$ \\
Neurologic disease & $11(15,7 \%)$ & $37(16,6 \%)$ \\
Spine & $6(8,6 \%)$ & $15(6,7 \%)$ \\
Obesity & $1(1,4 \%)$ & $11(4,9 \%)$ \\
Cachexia & $1(1,4 \%)$ & $1(0,4 \%)$ \\
\hline
\end{tabular}

mean age of 74.7 years [25]. Raunest et al. also calculated the 1-year mortality after a proximal femur fracture [26]. With an average age of 78.7 years, they reported $27.3 \%$ who died within 12 months. A 1-year mortality of $11.7 \%$ was given by Röder et al. [2]. Smektala et al. examined the prognosis of a femoral neck fracture [23]. They found a mortality after 12 months of $24.2 \%$. Lögters et al. published a 1-year mortality rate of $35.3 \%$ with a high average age of 86 years [10]. In their study, Holvik et al. stated a 1year mortality rate of $23.5 \%$, with a high mean age of 85 years [27]. Smektala et al. confirmed that patients with a higher ASA classification have a significantly poorer survival [23]. Holvik et al. also examined the difference in the ASA classification between the survivors and the deceased after 1 year [27]. With $46.2 \%$ compared to $69.2 \%$, significantly fewer surviving study patients had the ASA III or IV classification. Daugaard et al. were able to show that an increasing ASA classification means a risk increase for the outcome "death during inpatient stay" of 2.3 per level [24]. Davis et al. confirmed the influence of the ASA level on mortality, as did Uzoigwe et al. [3, 28].

In light of our analysis and the above-mentioned literature reports as well as further reports [16-19, 29, 30], we can state that it is highly recommendable to surgically treat patients over 90 years with proximal femoral fracture in hospitals that are equipped with maximum infrastructure for dealing with such cases. Though many literature reports notably stress on the necessity to operate within less than $24 \mathrm{~h}[16-19,29,30]$, we could not observe any benefits in those patients treated within the first $24 \mathrm{~h}$ of admission. Interestingly, the time period between admission and surgery was clinically significantly shorter in very old patients who died and those who survived without being statistically different. This might suggest that a thorough preoperative conditioning can lower the incidence of postoperative mortality in patients over 90. This was also observed by Zajonz et al. [20]. Therefore, patients over 90 years with proximal femoral fracture should be optimally prepared for surgery even though this might prevent operative stabilization within $24 \mathrm{~h}$ after admission. Additionally, patients will benefit from a hospital setup that is able to provide sufficient surgical experience, medical, welleducated anesthesiologic and nursing staff for very old patients and an adequate infrastructure as well as intensive care capacity. The intersection of geriatric traumatology with other specialist disciplines, especially acute geriatrics, will be of enormously increasing importance in the future.

Schiavone et al. [31] investigated the use of tranexamic acid in the management of peritrochanteric femoral fracture. They concluded that the use of tranexamic acid was statistically significant in reducing postoperative blood loss. Yet, the mortality in the study population of patients over 75 was linked more to the chronic inflammatory state and comorbidities rather than to the use of tranexamic acid.

Studies have shown that periprosthetic or postoperative infections can shorten life expectancy [32, 33].

Table 4 Demographics of the very old patients who died during the inpatient stay

\begin{tabular}{lllllll}
\hline Patient & Age & AO-C & Treatment strategy & Time: admission to surgery & Comorbidities & Complications \\
\hline 1 & 92 & A1 & DHS & $18 \mathrm{~h}: 09$ & dementia & ARF, Ml \\
2 & 90 & A1 & DHS & $12 \mathrm{~h}: 07$ & dementia; HT; LE.; h/O PE & none \\
3 & 92 & A2 & Nail & $8 \mathrm{~h}: 04$ & DM; HT, COPD & ARF \\
4 & 94 & A1 & Nail & $19 \mathrm{~h}: 55$ & h/o PE; COPD & UTI, pneumonia \\
5 & 95 & A2 & DHS & $12 \mathrm{~h}: 03$ & HT; AF; DM; PAOD & none \\
6 & 93 & A2 & Nail & $15 \mathrm{~h}: 12$ & HT; AF; h/o; malignancy & none \\
\hline
\end{tabular}

AO-C Classification of the fracture in accordance to the AO; Time: admission to surgery Time between admission and begin of surgery in hours, DHS Dynamic hip screw, Nail Proximal femoral nail, $H T$ Hypertension, LE Lupus erythematodes, $h / o$ History of, PE Pulmonary embolism, DM Diabetes mellitus, COPD Chronic obstructive pulmonary disease, AF Atrial fibrillation, PAOD Peripheral artery occlusive disease, ARF Acute renal failure, MI Myocardial infarction, UTI Urinary tact infection 


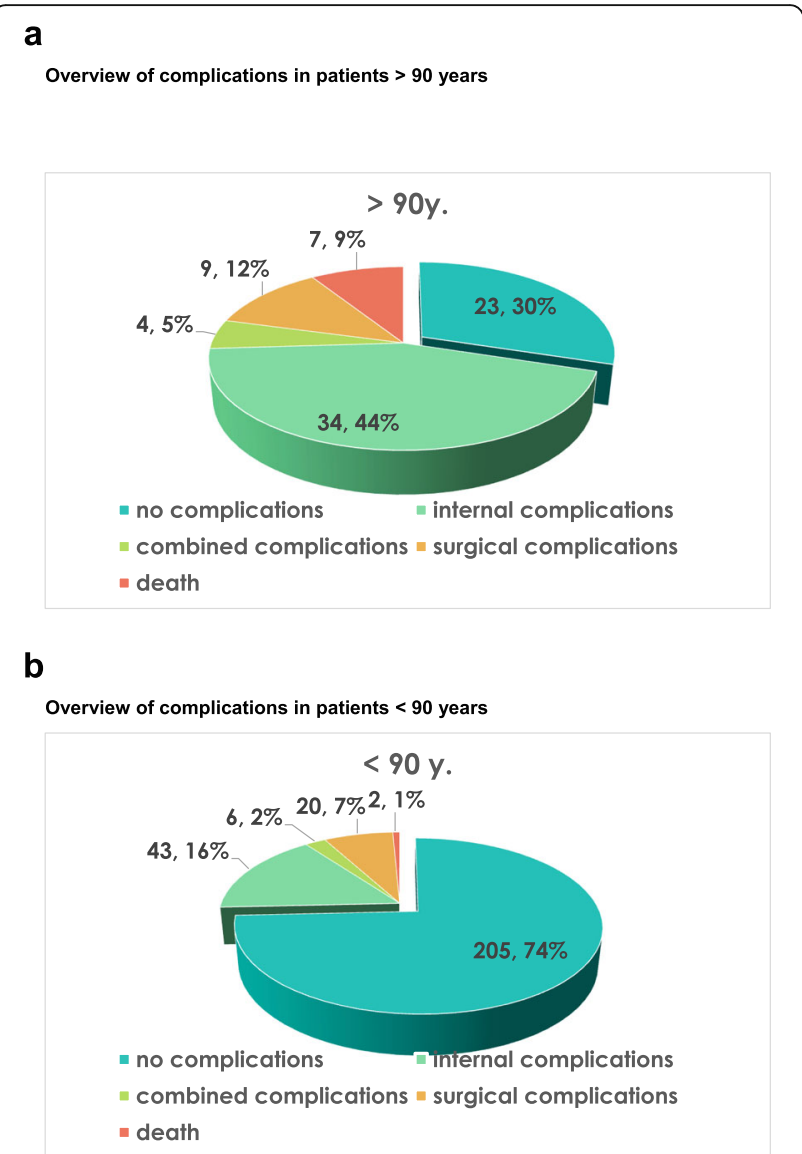

Fig. 1 Overview of complications in patients $>90$ years

Falzarano et al. suggest the use of seriated controls of Creactive protein, erythrocyte sedemantion rate and procalcitonin for patients undergoing total hip arthroplasty in the first 4 weeks after surgery to detect and manage infection as early as possible. The regular investigation of these parameters should be considered in management of proximal femoral fractures to monitor patients concerning infection as possible complication that can have impact on life expectancy, especially in the elderly.

Concerning stability of the proximal femur following surgery, studies did not show a direct relation between the degree of stability and life expectancy $[34,35]$. Lanzetti et al. demonstrated that in intertrochanteric $31-\mathrm{A} 1$ and 31-A2 stable fractures, the absence of distal locking screw does not compromise bone healing and prevents several clinical complications. Yet, Maiettini et al. concluded that increasing the use of blinded assessment of outcomes and improved reporting of reliability of subjective end points will improve the quality of interferences derived from clinical studies.

The currently available data do not allow for drawing definite conclusion concerning the impact of revision surgery on life expectancy. Yet, some studies retrospective studies have shown a higher tendency of poor functional outcomes and complications that led to death following revision surgery in elderly patients [36-38].

The limitation of this study lies in its retrospective design and the short follow-up period that is limited to inhospital stay. Though we considered the number of daily medications administered and have shown no impact on the outcome, we did not analyze the type of medications due to the heterogeneity of medications administered. However, to the best of our knowledge, very few studies have dealt with proximal femoral fractures in patients over 90 years $[39,40]$. In contrast to these studies, we included a control group. Yet, the control group comprised of patients aged 60 to 90, which bares considerable heterogeneity and thus must be viewed as a further limitation. Thus, further studies with comparison with similar age and gender can reveal more precise data.

\section{Conclusion}

Surgical management of pertrochanteric fractures in patients over 90 years seems to be associated with higher incidence of postoperative complications. According to our study, the number of co-morbidities, number of daily-administered medications and the time between admission and surgery might have no impact on the outcome. Contrary to previous studies, we noticed a longer period between admission and surgery in very old patients who survived. Therefore, further studies are needed to analyze the outcome of surgical management of pertrochanteric fractures in the 10th decade of life, particularly with regards to timing of surgical intervention and the extent of preoperative conditioning. Further, patients with pertrochanteric fractures should be screened for multimorbidity and cognitive disorders in a standardized manner.

\section{Abbreviations}

AO: Arbeitsgemeinschaft für Osteosynthesefragen; ASA: American Society of Anesthesiologists; ICD: International Statistical Classification of Diseases and Related HealthProblems; h: Hour

\section{Authors' contributions}

M.G. and U.S. have wrote the main manuscript text. J.G., A. R. and A.A-S. have prepared tables and figures and contributed to analyzing data. All authors reviewed the manuscript. The author(s) read and approved the final manuscript.

\section{Funding}

The authors received no financial support for the research, authorship, and/ or publication of this article. Open Access funding enabled and organized by Projekt DEAL.

\section{Availability of data and materials}

The datasets used and/or analyzed during the current study are available from the corresponding author on reasonable request. 


\section{Declarations}

\section{Ethics approval and consent to participate}

Approval of the local institutional review board for study had been given (Ethical Committee at the Medical Faculty, Leipzig University, AZ 166-20-ek) in view of the retrospective nature of the study and all the procedures being performed were part of the routine care. All individuals have given general consent in the use of their data, including imaging, for analysis and publication. This has been approved by the Ethical Committee.

\section{Consent for publication}

All individuals have given general consent in the use of their data, including imaging, for analysis and publication. This has been approved by the Ethical Committee.

\section{Competing interests}

The authors declare no conflict of interest with respect to research, authorship, and/or publication of this article.

\section{Received: 9 August 2021 Accepted: 31 August 2021}

Published online: 16 September 2021

\section{References}

1. Joosse P, Loggers SAI, Van de Ree CLPM, et al. The value of nonoperative versus operative treatment of frail institutionalized elderly patients with a proximal femoral fracture in the shade of life (FRAIL-HIP); protocol for a multicenter observational cohort study. BMC Geriatr. 2019;19(1):301. Published 2019 Nov 8. https://doi.org/10.1186/s12877-019-1324-7.

2. Röder F, Schwab M, Aleker T, Mörike K, Thon K-P, Klotz U. Proximal femur fracture in older patients - rehabilitation and clinical outcome. Age Ageing. 2003;32(1):74-80. https://doi.org/10.1093/ageing/32.1.74.

3. Stöckle U, Lucke M, Haas NP. Zertifizierte medizinische Fortbildung: Der Oberschenkelhalsbruch. Dtsch Arztebl. 2005;102:3426-34.

4. Becker C, Gebhard F, Muche R, Scheible S, Nikolaus T. Epidemiologie von Stürzen Älterer. Z Orthop. 1999;137(06):482-5. https://doi.org/10.1055/s-2 008-1039375.

5. Becker C, Gebhard F, Fleischer S, Hack A, Kinzl L, Nikolaus T, et al. Prädiktion von Mortalität und soziofunktionellen Einschränkungen nach proximalen Femurfrakturen bei nicht institutionalisierten Senioren. Unfallchirurg. 2003; 106(1):32-8. https://doi.org/10.1007/s00113-002-0475-7.

6. Lohmann R, Haid K, Stöckle U, Raschke M. Epidemiologie und Perspektiven der Alterstraumatologie. Unfallchirurg. 2007;110(6):553-60. https://doi.org/1 0.1007/s00113-007-1286-7.

7. Lohmann R, Frerichmann U, Stöckle U, Riegel T, Raschke MJ. Proximale Femurfrakturen im Alter. Auswertung von Krankenkassendaten von über 23 Mio. Versicherten--Teil 1. Unfallchirurg. 2007;110(7):603-9. https://doi.org/1 0.1007/s00113-007-1257-z.

8. Lein T, Bula P, Straßberger C, Bonnaire F. Proximale Femurfrakturen. Trauma Berufskrankh. 2011;13(S1):107-16. https://doi.org/10.1007/s10039-011-1792-2.

9. Dubey A, Koval KJ, Zuckerman JD. Hip fracture prevention: a review. Am J Orthop. 1998;27(6):407-12

10. Lögters T, Hakimi M, Linhart W, Kaiser T, Briem D, Rueger J, et al. Die geriatrische Frührehabilitation nach hüftgelenknahem Oberschenkelbruch: Nachhaltiges Konzept oder lediglich Kostenverschiebung? Unfallchirurg. 2008;111(9):719-26. https://doi.org/10.1007/s00113-008-1469-x.

11. Arbeitsgruppe der Bundesarbeitsgemeinschaft der Klinisch-Geriatrischen Einrichtungen e.V., der Deutschen Gesellschaft für Geriatrie e.V. und der Deutschen Gesellschaft für Gerontologie und Geriatrie e.V. (2004) Abgrenzungskriterien der Geriatrie Version V1.3 http://www.geriatrie-drg. de/public/docs/Abgrenzungskriterien_Geriatrie_V13_16-03-04.pdf [Stand: 24.09.2012]

12. Deutsche Gesellschaft für Geriatrie (DGG) (2012). Was ist Geriatrie? http:// www.dggeriatrie.de/nachwuchs/was-ist-geriatrie.html [Stand: 24.09.2012]

13. Mayhew D, Mendonca V. Murthy BVS (2019). A review of ASA physical status - historical perspectives and modern developments. Anaesthesia. 2019;74(3):373-9. https://doi.org/10.1111/anae.14569.

14. Borchelt M, Wrobel N, Trilhof G (2009) Online-Kodierleitfaden Altersmedizin 2009. http://www.geriatrie-drg.de/dkger/main/kodierleitfaden-2009.html [Stand: 24.09 .2012 ]
15. Meinberg EG, Agel J, Karam MD RCS, Kellam JF. Fracture and dislocation classification compendium - 2018. J Orthop Trauma. 2018;32(Suppl 1):S1S170. https://doi.org/10.1097/BOT.0000000000001063.

16. Hamlet WP, Lieberman JR, Freedman EL, Dorey FJ, Fletcher A, Johnson EE. Influence of health status and the timing of surgery on mortality in hip fracture patients. Am J Orthop. 1997;26(9):621-7.

17. Hill CE, Shapey IM, Eales F, McKloskey G, Costa ML. Theatre within $36 \mathrm{~h}$ for patients with fracture of the proximal femur: can we deliver? Arch Orthop Trauma Surg DOI. 2012;133(3):367-71. https://doi.org/10.1007/ s00402-012-1675-4.

18. Smektala R, Hahn S, Schrader P, et al. Medial hip neck fracture: influence of pre-operative delay on the quality of outcome. Results of data from the external in-hospital quality assurance within the framework of secondary data analysis. Unfallchirurg. 2010;113(4):287-92. https://doi.org/10.1007/ s00113-009-1674-2.

19. Villar RN, Allen SM, Barnes SJ. Hip fractures in healthy patients: operative delay versus prognosis. Br Med J (Clin Res Ed). 1986;293(6556):1203-4. https://doi.org/10.1136/bmj.293.6556.1203.

20. Zajonz D, Brand A, Lycke C, Özkurtul O, Theopold J, Spiegl UJA, et al. Risk factors for early infection following hemiarthroplasty in elderly patients with a femoral neck fracture. Eur J Trauma Emerg Surg. 2019;45(2):207-12. https://doi.org/10.1007/s00068-018-0909-8.

21. Costa ML, Griffin XL, Pendleton N, Pearson M, Parsons N. Does cementing the femoral component increase the risk of peri-operative mortality for patients having replacement surgery for a fracture of the neck of femur? J Bone Joint Surg Br. 2011;93-B(10):1405-10. https://doi.org/10.1302/0301-62 OX.93B10.26690.

22. Smektala R, Wenning M, Ekkernkamp A. Schenkelhalsfraktur: Analyse der Ergebnisse externer Qualitätssicherung. Chirurg. 1999;70(11):1330-9. https:// doi.org/10.1007/s001040050788.

23. Smektala R, Ohmann C, Paech S, Neuhaus E, Rieger M, Schwabe W, et al. Zur Prognose der Schenkelhalsfraktur. Beurteilung der Mortalitat nach Schenkelhalsfraktur durch sektorubergreifende Datenzusammenfuhrung. Unfallchirurg. 2005;108(927-928):930-7. https:// doi.org/10.1007/s00113-005-0972-6.

24. Daugaard $\mathrm{CL}$, Jørgensen $\mathrm{HL}$, Riis T, Lauritzen JB, Duus BR, Mark S. Is mortality after hip fracture associated with surgical delay or admission during weekends and public holidays? Acta Orthop. 2012;83(6):609-13. https://doi. org/10.3109/17453674.2012.747926.

25. Simanski C, Bouillon B, Lefering R, Zumsande N, Tiling T. Welche Prognosefaktoren korrelieren mit der Alltagsaktivität (Barthel-Index) ein Jahr nach hüftgelenksnaher Fraktur? Unfallchirurg. 2002;105(2):99-107. https:// doi.org/10.1007/s001130100285.

26. Raunest J, Engelmann R, Jonas M, Derra E. Morbidität und Letalität bei hüftgelenknahen Femurfrakturen im höheren Lebensalter. Unfallchirurg. 2001;104(4):325-32. https://doi.org/10.1007/s001130050735.

27. Holvik K, Ranhoff AH, Martinsen Ml, Solheim LF. Predictors of mortality in older hip fracture inpatients admitted to an orthogeriatric unit in Oslo, Norway. J Aging Health. 2010;22(8):1114-31. https://doi.org/10.1177/08982 64310378040

28. Davis FM, Woolner DF, Frampton C, Wilkinson A, Grant A, Harrison RT, et al. Prospective, multi-Centre trial of mortality following general or spinal anaesthesia for hip fracture surgery in the elderly. Br J Anaesth. 1987:59(9): 1080-8. https://doi.org/10.1093/bja/59.9.1080.

29. Cooper C, Campion G, Melton LJ. Hip fractures in the elderly: a world-wide projection. Osteoporos Int. 1992;2(6):285-9. https://doi.org/10.1007/BF01 623184.

30. Uzoigwe CE, Burnand HG, Cheesman CL, Aghedo DO, Faizi M, Middleton RG. Early and ultra-early surgery in hip fracture patients improves survival. Injury DOI. 2012;44(6):726-9. https://doi.org/10.1016/j.injury.2012.08.025.

31. Schiavone A, Bisaccia M, Inkov I, Rinonapoli G, Manni M, Rollo G, et al. Tranexamic acid in Pertrochanteric femoral fracture: is it a safe drug or not? Folia Med (Plovdiv). 2018;60(1):67-78. https://doi.org/10.1515/folmed-20170070 PMID: 29668448

32. Rollo G, Logroscino G, Stomeo D, Cioffi R, Calvisi V, Meccariello L. Comparing the use of preformed vs hand-made antibiotic spacer cement in two stages revision of hip periprosthetic infection. J Clin Orthop Trauma. 2020;11(Suppl 5):S772-8. https://doi.org/10.1016/j.jcot.2020.08.003 Epub 2020 Aug 17. PMID: 32999554; PMCID: PMC7503155.

33. Falzarano G, Piscopo A, Grubor P, Rollo G, Medici A, Pipola V, et al. Use of common inflammatory markers in the long-term screening of total hip 
arthroprosthesis infections: our experience. Adv Orthop. 2017;2017:9679470. https://doi.org/10.1155/2017/9679470 Epub 2017 Aug 23. PMID: 29138696; PMCID: PMC5613705.

34. Lanzetti RM, Caraffa A, Lupariello D, Ceccarini P, Gambaracci G, Meccariello L, et al. Comparison between locked and unlocked intramedullary nails in intertrochanteric fractures. Eur J Orthop Surg Traumatol. 2018;28(4):649-58. https://doi.org/10.1007/s00590-018-2143-9 Epub 2018 Feb 9. PMID: 29427093.

35. Maiettini D, Bisaccia M, Caraffa A, Rinonapoli G, Piscitelli L, Bisaccia O, et al. Feasibility and value of radiographic union score hip fracture after treatment with intramedullary nail of stable hip fractures. Acta Inform Med. 2016;24(6):394-6. https://doi.org/10.5455/aim.2016.24.394-396 PMID: 28077901; PMCID: PMC5203746.

36. Rollo G, Pichierri P, Grubor P, Marsilio A, Bisaccia M, Grubor M, et al. The challenge of nonunion and malunion in distal femur surgical revision. Med Glas (Zenica). 2019;16(2). https://doi.org/10.17392/1016-19 Epub ahead of print. PMID: 31187611.

37. Rollo G, Bonura EM, Huri G, Ronga M, Carulli C, Bisaccia M, et al. Standard plating vs. cortical strut and plating for periprosthetic knee fractures: a multicentre experience. Med Glas (Zenica). 2020;17(1):170-7. https://doi. org/10.17392/1035-20 PMID: 31535543.

38. Rollo G, Tartaglia N, Falzarano G, Pichierri P, Stasi A, Medici A, et al. The challenge of non-union in subtrochanteric fractures with breakage of intramedullary nail: evaluation of outcomes in surgery revision with angled blade plate and allograft bone strut. Eur J Trauma Emerg Surg. 2017;43(6): 853-61. https://doi.org/10.1007/s00068-016-0755-5 Epub 2017 Mar 3. PMID: 28258285.

39. Müller F, Galler M, Zellner M, Bäuml C, Füchtmeier B. The fate of proximal femoral fracture in the 10th decade of life: An analysis of 117 consecutive patients. Injury. 2015;46(10):1983-7. https://doi.org/10.1016/j.injury.2015.06.048.

40. Zhang Y, Huang L, Liu Y, Chen Q, Li X, Hu J. (2020). Prediction of mortality at one year after surgery for pertrochanteric fracture in the elderly via a Bayesian belief network. Injury. 2020;51(2):407-13. https://doi.org/10.1016/j. injury.2019.11.029 Epub 2019 Nov 21. PMID: 31870611.

\section{Publisher's Note}

Springer Nature remains neutral with regard to jurisdictional claims in published maps and institutional affiliations.

Ready to submit your research? Choose BMC and benefit from:

- fast, convenient online submission

- thorough peer review by experienced researchers in your field

- rapid publication on acceptance

- support for research data, including large and complex data types

- gold Open Access which fosters wider collaboration and increased citations

- maximum visibility for your research: over $100 \mathrm{M}$ website views per year

At $\mathrm{BMC}$, research is always in progress.

Learn more biomedcentral.com/submissions 